\title{
Effects of the authentic blended learning model in enhancing instructional media production capabilities for pre-service teachers
}

\author{
Nuttaphong Kanchanachaya, Prince of Songkla University, Thailand, kanchanachaya@gmail.com \\ Kanita Nitjarunkul, Prince of Songkla University, Thailand, Nkanita52@gmail.com \\ Virintorn Auksornnit, Prince of Songkla University, Thailand, virintorn5799@gmail.com
}

This work was supported by Prince of Songkla University [EDU570410S]

\begin{abstract}
This study aimed to investigate the effects of the authentic blended learning model in enhancing instructional media production capabilities for pre-service teachers. The sample included 50 undergraduate pre-service teachers in the Faculty of Education, Prince of Songkla University (i.e., 23 in the control group and 27 in the experimental group). The instruments were 1) an authentic blended lesson plan in enhancing instructional media production capabilities for pre-service teachers, 2) test on instructional media production capabilities for pre-service teachers, and 3) a satisfaction survey on the authentic blended learning model in enhancing instructional media production capabilities for preservice teachers. Data were statistically analyzed using arithmetic mean, standard deviation, and a t-test. Results revealed that the pre-service teachers who were exposed to the authentic blended learning model demonstrated higher instructional media production capabilities than the ones in the control group with statistical significance at the level of .05. Furthermore, they were highly satisfied with the constructed learning model, which was implemented with the experimental group $(\bar{x}=4.22$, S.D. $=0.668)$.
\end{abstract}

Keywords: Learning model, Blended learning, Authentic learning, Instructional media production capabilities, Pre-Service teachers

Received: 22.11.2020 $\quad$ Accepted: $10.12 .2020 \quad$ Published: 13.01 .2021

\section{INTRODUCTION}

All pre-service teachers in the Bachelor of Education are required to take courses to produce various types of instructional media. Currently, pre-service teachers learn through lectures and demonstrations in such courses as they progress towards course objectives. However, many pre-service teachers were found affected by such pedagogies as they appeared to lack the training for well-rounded thinking due to limited exposes to group processes. As a result, many of their constructed instructional media failed to address realistic learning conditions (Kanchanachaya, 2012). Instructional media are incredibly vital to education as they serve as a communication medium that transfer teachers' contents and experiences to students in a more effective way (Malithong, 2005). Through this significance, education institutions should prioritize and expedite the development of practical media for instructional implementations. However, current teaching practices show that the utilization of such media has been struggling and problematic, e.g., existing quantity does not match the needs for each subject, being vulnerable to damages, being incomplete in content coverages, being obsolete, being unattractive to students, being poor in variety, being unsuitable due to classroom conditions, and being inapplicable due to insufficient instructors' skills in production and systematic media implementation (Songmuang, 2008). Furthermore, the current teaching problems, as described above, are consistent with the initial survey data, i.e., preservice teachers, via a self-evaluation, were assessed as lacking necessary problem-solving skills in choosing and producing instructional media amid practical situations such as during in-school preservice teaching. More specifically, they were insufficient in analytical, synthetic, critical, creative, and reflective thinking. Consequently, when all these skills were missing, they failed to realistically think, analyze, and decide when choosing and producing instructional media for the real-world management for specific courses and students. This inadequacy was caused by the lack of classroom knowledge and experiences, and such incompetence was a barrier to problem-solving (Kanchanachaya, 2012).

The National Education Act, BE 2542 (1999) places emphasis on the provision of quality education by positioning students at the center of educational attention, promoting thinking and practical capabilities, organizing activities based on tangible experiences, encouraging teachers to tone their teaching atmospheres and environments, fostering teachers to simultaneously learn along with their 
students from surrounding instructional media, knowledge sources, and inviting them to incorporate local learning resources in learning organizations to enhance students' skills, thinking processes, management skills, and application skills that could be adapted for the prevention and problem-solving in real-life situations (Government Gazette, 1999).

Hence, in future educational management, instructor need to modify their teaching styles to offer students more opportunities to develop problem-solving skills. To enable these skills, instructions should focus on student-centered education, where they are encouraged to progress through individual development the natural way at their maximum potential. Instructions should be diversified to address real situations, and teachers should serve as a facilitator in such experiences. Critical and systematic thinking processes should be introduced with the purposes to help students integrate and make connections between bodies of knowledge, and bridge in-class knowledge to situational applications (Waisurasing \& Noparoojjinda, 2011). Authentic learning is deemed to be a vital strategy that instructor should explore when transforming perspectives and developing students towards national quality standards.

Authentic learning is a teaching paradigm that combines situational or real-world activities and interactions. Instructor incorporate them into teaching and assessment to stimulate students to think and develop a deeper understanding, while the teachers stay take passive roles as a supporter of their search for knowledge (Waisurasing \& Noparoojjinda, 2011). In addition to authentic learning, which promotes logical associations, students should simultaneously be equipped with relevant competencies to be a member of learning societies. To transition students to a learning society, classroom experiences alone do not suffice as e-learning is equally another essential. Technological pedagogical content knowledge (TPCK) perceives that contents, pedagogies, and technology blended to maximize learning benefits (Suwannatthachote, 2008). To introduce both classroom and e-learning experiences to students, integrated instructions are necessary. Blended teaching and learning combines regular classroom experiences with online network learning through technological facilitation, where online platforms are employed as tools for knowledge exchanges between learners and various data queries (Long, 2007). Therefore, learning autonomy is key to blended learning as it exposes students to a wide array of knowledge. In general, authentic blended learning combines classroom and online learning, focuses on offering a variety of pedagogies with real-life situations, promotes critical and systematic thinking processes, incorporates technology as a medium for learning activities, and positions teachers with support roles. Hence, authentic blended learning is considered suitable as an educational model for a 21st century learning skill, which is, as Lombardi (2007) stated, the most effective teaching method of the 21st century is authentic learning as it is based on practices. Using the internet and modern communication methods would help visualize knowledge through diverse learning simulations. Today's technology is significantly helpful as a tool for authentic learning experiences in 21st century education.

Hence, employing situations or problems to provoke thoughts while learning could lead to autonomous learning inquiries, whereas group processes would encourage students to review existing knowledge and build up new knowledge. Cognitive theories explain human behaviors through a perception that humans usually adopt the best way to think and choose the best options. In the perception of constructionism, learning is a process that internally occurs within learners as they enable themselves to think creatively and critically through self-reliance and constructive cooperation and integrate such knowledge for a harmonious living (Kemil, 1991; Noddings, 1990; Von Glasserfeld, 1991; Henderson, 1992, as cited in Sekkhunthod, 2016).

Consequently, the researcher was keen to investigate the effects of the authentic blended learning model in enhancing instructional media production capabilities for pre-service teachers.

\section{METHODS}

\section{Step 1: The development of the authentic blended learning model in enhancing instructional media production capabilities for pre-service teachers}

\section{Developmental procedures}

The model was constructed based on the multi-phase ADDIE Model, which includes analysis, design, development, implementation, and evaluation. A review of the literature was initially conducted on documents and studies that are relevant to the development of authentic blended learning for instructional media production capabilities. The relevancy was considered by learners' skills and competencies, course contents, teaching activities, learning environments, and technological integration. Subsequently, a draft authentic blended learning model was designed and constructed purposely to boost instructional media production capabilities through authentic instructions in five steps, i.e., preparation 
and review of basic knowledge, introduction to new knowledge, fact-finding through systematic data collection, planning and implementation of learning activities, and discussion, exchanges of opinions, and evaluation of learning. Later, the constructed draft was submitted for validation on correctness and suitability by experts and modified as suggested, whereas the revised model was implemented with the sample.

\section{Research Instrument}

A quality assessment was employed to validate the authentic blended learning model in enhancing instructional media production capabilities for pre-service teachers.

\section{Results}

The model went through a quality assessment from three experts and found that it received the quality scores that could be interpreted as highly suitable ( $\overline{\mathrm{x}}=4.33$, S.D. $=0.477)$.

Table 1. Authentic Blended Learning Model in Enhancing Instructional Media Production capabilities for Pre-Service Teachers

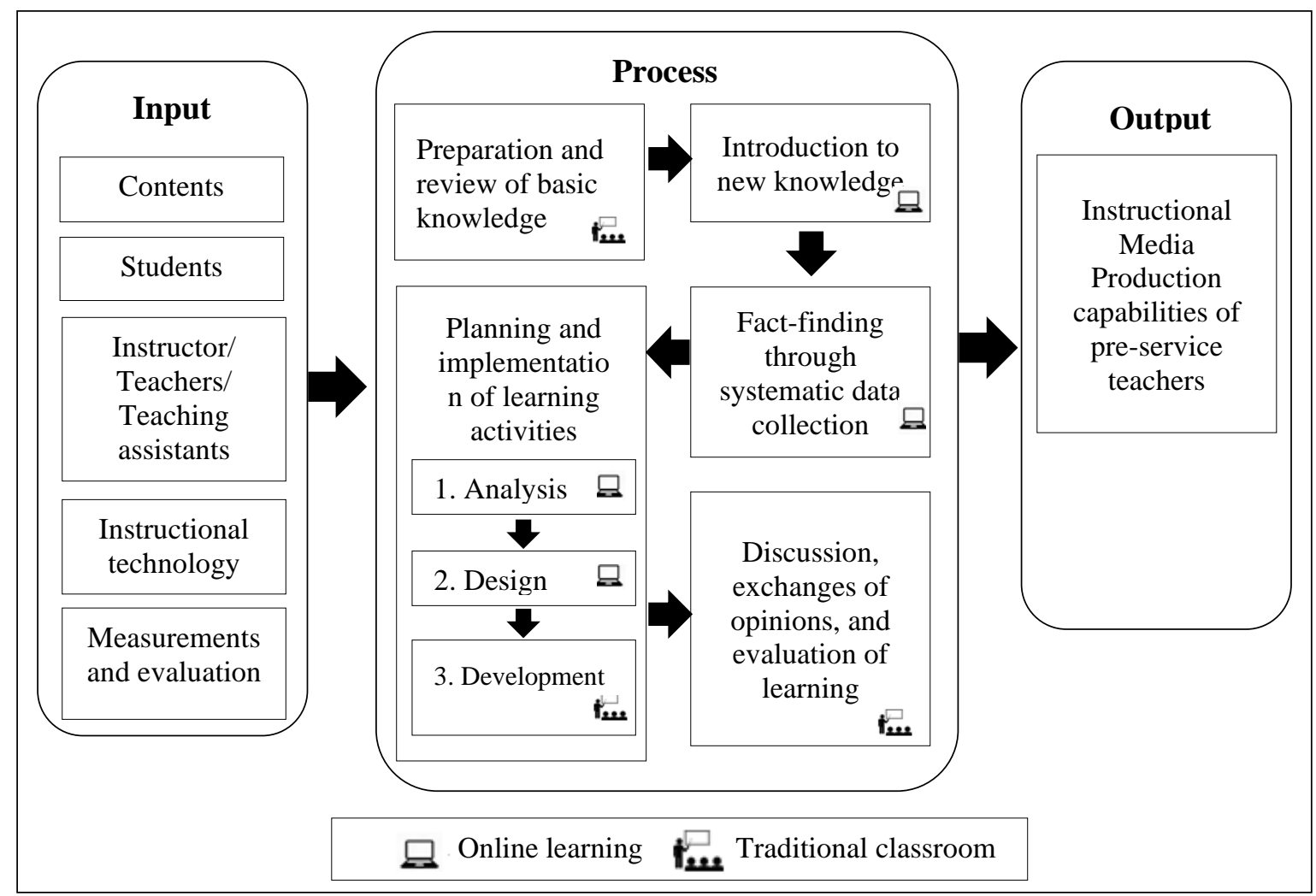

From figure 1 found Authentic Blended Learning Model in Enhancing Instructional Media Production capabilities for Pre-Service Teachers consist of 3 elements are (1) input (2) process and (3) output in each elements have the following details

1. Its inputs included five components.

(1) Contents: The model contents should consist of practices, implementations, and production of instructional media, innovations, and information technology. Different presentation formats should be incorporated for both classroom and online instructions to enhance understand and practical applications.

(2) Students: The students should be enthusiastic when doing activities, maintain self-discipline, autonomously build up the understanding of learning procedures, activities, and problems, examine the assigned knowledge contents, and submit work within required time frames.

(3) Instructor/ Teachers/ Teaching assistants: These instructors should specialize in the subject matters, regularly search for and introduce for new sources of information to students and possess the abilities to transfer knowledge. 
(4) Instructional technology: The Learning Management System (LMS) and online instructional media should be the tools that facilitate the learning and transfers of skills, knowledge, and experiences from the instructors to the students.

(5) Measurements and evaluation: The students should go through tests before, during, and after studying.

2. Furthermore, there are five steps to the instructional process in the authentic blended learning model, which employed classroom and online learning.

(1) Preparation and review of basic knowledge: In this step, both the instructors and the students prepared themselves for the sessions by familiarizing the process, methods, and procedures for upcoming learning activities. The preparation was conducted in class.

(2) Introduction to new knowledge: The students were exposed to new content based on the course objectives. More specifically, they went over predetermined topics about ways to produce instructional media. Online learning was implemented for this step.

(3) Fact-finding through systematic data collection: Thought-provoking problems were introduced to the class, whereas the students were encouraged to identify facts and explore realistic situations that might occur in the teaching. This step incorporated online learning.

(4) Planning and implementation of learning activities: The students improved skills in instructional media production and problem-solving in authentic situations as existing knowledge was being integrated and applied. This step was conducted in class and online.

(5) Discussion, exchanges of opinions, and evaluation of learning: The instructors and students discussed and shared ideas in assessing the quality of the developed instructional media. This step was done in class.

3. As a result, the students demonstrated the following capabilities in producing instructional media

(1) problem analysis capabilities through sub-skills, i.e., the abilities to understand problems, compile solutions, analyze emerging problems, prioritize issues, make assumptions about problems, decide the most appropriate solutions to the problems, and recognize problematic conditions;

(2) instructional media designs capabilities through sub-skills, i.e., the abilities to understand contents, draw conceptual summaries, establish behavioral objectives, specify inclusion criteria for problem-solving methods, and draft appropriate instructional media formats to address the problemsolving; and

(3) instructional media development capabilities through sub-skills, i.e., the ability to construction the instructional media that could solve problems.

\section{Step 2: Investigating effects of the authentic blended learning model in enhancing instructional media production capabilities for pre-service teachers}

\section{Data collection}

In this study, the pre-service teachers were divided into two groups, i.e., control and experimental. Those who were in the control group went through regular teaching activities, whereas the ones in the experimental group were exposed to the authentic blended learning model. During the class, the experimental pre-service teachers were informed about the research objectives. Subsequently, they were task to do a pre-test, which measured their instructional media production capabilities and proceeded with the learning as planned. Once the learning activity was finished, they took a post-test to reevaluate their instructional media production capabilities and took a satisfaction survey to report their levels of satisfaction with the model. The data were then compiled for further analysis.

\section{Research Instruments}

1. The authentic blended lesson plan in enhancing instructional media production capabilities for preservice teachers with extremely high suitability $(\bar{x}=4.57$, S.D. $=0.389)$.

2. Online authentic blended instructional media in enhancing instructional media production capabilities for pre-service teachers with extremely high suitability $(\overline{\mathrm{x}}=4.61$, S.D. $=0.458)$.

3 . The measurement on instructional media production capabilities for pre-service teachers (IOC=0.661.00).

4. The satisfaction survey on the authentic blended learning model in enhancing instructional media production capabilities for pre-service teachers $(\mathrm{IOC}=0.66-1.00)$.

\section{Data analysis}

The data were statistically analyzed using arithmetic mean, standard deviation, and a t-test. 


\section{RESULTS}

\section{As the authentic blended learning model in enhancing instructional media production capabilities for pre-service teachers}

As the authentic blended learning model in enhancing instructional media production capabilities for preservice teachers was implemented on the undergraduates in the Faculty of Education, Prince of Songkla University, who were enrolled in their first semester of Academic Year 2016 in 263-201 Innovation and Educational Technology, the results revealed the following

Table 1. As the authentic blended learning model in enhancing instructional media production capabilities for pre-service teachers, in the control and experimental groups instructional media production capabilities score.

\begin{tabular}{|llcccc|}
\hline $\begin{array}{l}\text { Post test Instructional } \\
\text { media production } \\
\text { capabilities score }\end{array}$ & $\mathbf{n}$ & $\overline{\mathbf{x}}$ & S.D. & $\mathbf{t}$ & Sig. \\
\hline Control Group & & & & & \\
Experimental Group & 23 & 15.26 & 2.359 & -7.842 & 0.000 \\
\hline
\end{tabular}

From table 1 found the students, in the control and experimental groups, demonstrated differences in instructional media production capabilities with statistical significance. Post-test scores obtained from the control group indicated an arithmetic mean ( $\mathrm{x}^{-}$) of 15.26 and a standard deviation (S.D.) of 2.359, whereas the experimental group earned an arithmetic mean ( $\left.\mathrm{x}^{-}\right)$of 21.04 and a standard deviation (S.D.) of 2.780 .

Table 2. As the authentic blended learning model in enhancing instructional media production capabilities for pre-service teachers, in the experimental group satisfaction score.

\begin{tabular}{|c|c|c|c|}
\hline Items & $\overline{\mathbf{x}}$ & S.D. & Satisfaction level \\
\hline $\begin{array}{l}.1 \text { The activities facilitated the learning } \\
\text { and promoted autonomous thinking skills }\end{array}$ & 4.04 & 0.587 & High \\
\hline $\begin{array}{l}.2 \text { the teaching methods were suitable for } \\
\text { the course contents }\end{array}$ & 4.11 & 0.801 & High \\
\hline $\begin{array}{l}.3 \text { the model enhanced the understanding } \\
\text { of the lesson }\end{array}$ & 4.15 & 0.662 & High \\
\hline $\begin{array}{l}.4 \text { the model created an atmosphere that } \\
\text { made the lesson interesting }\end{array}$ & 4.33 & 0.620 & High \\
\hline $\begin{array}{l}.5 \text { the model stimulated constant teacher- } \\
\text { student and student-student interactions } \\
\text { and communication }\end{array}$ & 4.15 & 0.718 & High \\
\hline .6the types of interactions were appropriate & 4.37 & 0.688 & High \\
\hline 7. the tools for interactions were suitable & 4.15 & 0.718 & High \\
\hline $\begin{array}{l}\text { 8. the model encouraged the students } \\
\text { to participate in the learning process }\end{array}$ & 4.37 & 0.688 & High \\
\hline $\begin{array}{l}\text { 9. the activities were organized in a way } \\
\text { that it encouraged the students to take part } \\
\text { and think analytically }\end{array}$ & 4.30 & 0.669 & High \\
\hline $\begin{array}{l}\text { 10. the employed media technology and } \\
\text { innovations appropriately promoted } \\
\text { the learning }\end{array}$ & 4.26 & 0.526 & High \\
\hline Total & 0.668 & & \\
\hline
\end{tabular}

From table 2 found Their satisfaction with the model was extremely high $(\bar{x}=4.22$, S.D. $=.(0.668$

\section{DISCUSSION AND CONCLUSIONS}


Based on the effects of the authentic blended learning model, it was found that the pre-service teachers in the experimental group demonstrated higher instructional media production capabilities than those on the control group, as a statistical significance at the level of .05 as the hypothesis and their satisfaction with the model was extremely high. The phenomena could be explained through the unique characteristics of this model, i.e., the pre-service teachers being able to autonomously and conveniently study the contents at any time and from any place, the learning process being systematically organized through online instructional media and group interactions, and every step of the learning model being based on authentic conditions which encouraged the pre-service teachers to learn and practice together in realistic situations, problems, and contexts. Through this learning process, the pre-service teachers had opportunities to autonomously analyze, design, develop, implement, and evaluate. As a result, there as a higher chance for their understanding, enthusiasm, happiness, and practical success to improve based on individual potential. Furthermore, when the pre-service teachers took action, in reality, the authentic conditions enhanced their responsibilities, convinced perceivable benefits in studying, boosted confidence, and stimulated efforts for self-development. This type of learning is a suitable educational model for a 21st century education, which is as Lombardi (2007) stated, authentic learning through hands-on practices via the communicative facilitation of internet and technology give pre-service teachers of the 21st century a true learning experience while staying connected with teachers in their practical attempts following other group members in steps. Such settings create casual, relaxing, and stress-relieving learning atmospheres and enable activities for autonomous learning through a step-bystep approach. Consequently, these factors help students develop abilities and skills to perform their work more efficiently. The more students are involved in activities, the bigger roles they take in their learning, and the more profound learning could be. Hence, the instructional designs that allow participation, authentic actions, and balanced development of left and right brain hemispheres could increase learning joy and enthusiasm. When learning is less boring, learning outcomes and achievements could also improve (Khattiyamarn, 2003; Kongpow, 2005; Kamanee, 2001; Wongsasom \& Bunterm, 2010).

The students' satisfaction with the constructed model was reportedly extremely high because the model was found to be adequately responsive. Also, it offers student-centered activities that gave the students the opportunities to independently practice and accumulate knowledge, allow time for thinking practices, encourage them to analyze assigned situations, case scenarios, and events. Furthermore, since the course contents within the model were effectively designed in parallel with practical activities, the students were able to understand them better with learning enthusiasm and happiness, as well as perform successfully through individual paces. As a result, the students were able to achieve the designated goals. On this note, Sarasi (2000) agreed that success is achievable when desired objectives are reached or when the final emotional states of success are imminent, and when the obtained knowledge is applicable in daily life. Sunee (1982) indicated that pedagogies should be designed to draw students' attention and suit their ability levels. Learning should not be too difficult or too easy to prevent students from feeling discouraged in learning. Classrooms and learning processes should be managed to constantly retain learning attention and promote learning satisfaction, enjoyment, and enthusiasm.

\section{SUGGESTIONS}

\section{Applications of the results}

To apply the authentic blended learning model in enhancing instructional media production capabilities, it is crucial to keep pre-service teachers under supervision. Instructors should constantly offer suggestions and relevant learning facilitation throughout sessions. They are also needed to smoothen group activities. Thus, instructors should consistently observe their student behaviors, especially during online learning, as some pre-service teachers might struggle during group activities. As learning difficulties are identified, instructors should intervene to help. When pre-service teachers are having problems with their work or group activities, instructors should walk them through the problem-solving and occasionally take control of the situations, e.g., clarify instructions, answer questions, and encourage pre-service teachers to express their opinions or speak up to ensure that communication among members promotes effectiveness in group activities. Moreover, instructors should inform pre-service teachers about how online sessions are scheduled so that pre-service teachers could plan accordingly for the activities.

\section{Extensions for future studies}

Instructors could adapt the authentic blended learning model in enhancing instructional media production capabilities to develop other competencies and with other target groups. 
Instructors might consider incorporating different theories in the teaching process when developing instructional media production capabilities.

\section{REFERENCES}

Malithong, G. (2005). Technology, Education, and Innovation. Bangkok: Arun Printing.

Songmuang, J. (2008). Status, Problems, and Needs for Instructional Media of Teachers in Islamic Private Schools in Southern Border Provinces. Journal of Social Sciences and Humanities, Prince of Songkla University Pattani Campus,14(1), 70-84.

Sarasi, J. (2000). Variables related to Satisfaction in Service from Nursing Personnel of Customers of Samitivej Hospital in Bangkok (Master's thesis in Educational Psychology). Bangkok: Srinakharinwirot University.

Kanchanachaya, N. (2012). Development of a Blended Learning Model based on Creative Problem-Solving Principles using Lateral Thinking to Enhance Creative Problem-Solving Abilities for Instructional Media Production of Pre-service Teachers (Doctoral dissertation in Educational Technology and Communications). Bangkok: Chulalongkorn University.

Kamanee, T., \& et al. (2001). The Development of School Learning Processes: A Multi-case Study(Research Report). Bangkok: Faculty of Education, Chulalongkorn University.

Suwannatthachote, P. (2008). The Integration of Technology and Instructions(Instructional document for 2716302 Instructional Designs and Management). Bangkok: Faculty of Education, Chulalongkorn University.

The Government Gazette. (1999). National Education Act BE 2542. Bangkok: Office of the National Education Commission, Office of the Prime Minister.

Waisurasing, L., \& Noparoojjinda, S. (2011). The Development of Instructional Model Using AuthenticLearning Approach to enhance Achievement and Critical Thinking Ability of Nursing Students, Boromarajajonani College of Nursing, Suphanburi. The Journal of Nursing and Education, Boromarajonani College of Nursing Suphan Buri, 4(3), 66-67.

Khattiyamarn, W. (2003). A Proposed Practical Alternatives of Authentic Instruction in General Curriculum and Instruction Course for the Faculty of Education Students (Doctoral Dissertation in General Curriculum and Instruction). Bangkok: Chulalongkorn University.

Wongsupankongpow, W. (2005). Development of an Instructional Model Based on Reigeluth's Elaboration Theory for Enhancing Content Accuracy, Task Expertise, and Transfer of Learning Abilities of Higher Education Level Students. The ability to transfer learning links of learners (Doctoral Dissertation, Doctor of Education in Curriculum and Instruction). Bangkok: Chulalongkorn University.

Sekkhunthod, S. (2016). A Blended Problem-based Learning Model to Develop Students' Ethics and Learning Retention. Chachoengsao: Rajabhat Rajanagarindra University

Sunee, T. (1982). Educational Psychology. Nonthaburi: Pak Kret Women's Foster Home.

Wongsasom, U. \& Bunterm, T. (2010). The Effects of the 4MAT Cycle Learning Activities on the Body System Topic for Mathayomsuksa II Students (Master's Thesis in Education). Khon Kaen: Khon Kaen University.

Long, G., Vignare, K., Rappold, R., \& Mallory, J. (2007). Access to Communication for Deaf, Hard-of- Hearing and ESL Students in Blended Learning Courses. International Review of Research in Open and Distance, 8(3), 13.

Marilyn M. L. (2007). Authentic Learning for the 21st Century. Retrieved 2020, March 31, from: https://www.researchgate.net/publication/220040581_Authentic_Learning_for_the_21st_Centur y_An_Overview 